\title{
Eastern wild turkey nest site selection in two frequently burned pine savannas
}

\author{
Andrew R. Little ${ }^{1 *}$, Nathan P. Nibbelink¹, Michael J. Chamberlain ${ }^{1}$, L. Mike Conner ${ }^{2}$ and Robert J. Warren ${ }^{1}$
}

\begin{abstract}
Introduction: Reproductive success is a critical factor affecting avian demographics and can be influenced by many factors including nesting chronology, predation risk, and fine-scale nest site selection.

Methods: We modeled the relative influences of habitat-related covariates at six spatial scales (nest site: 15-, 40-, 80-, 120-, 160-, and 200-m radii) on Eastern wild turkey (Meleagris gallopavo silvestris) nest site selection in two pine savannas managed by frequent prescribed fire ( $\leq 3$ years) in southwestern Georgia during 2011-2013.

Results: Nest site (15-m scale) habitat metrics (mean visual obstruction [cm] and canopy closure [\%]) had the greatest influence on nest site selection relative to covariates measured at larger spatial scales. Scaled odds ratios suggested that nests were $26.8 \%$ more likely to occur for every $10 \mathrm{~cm}$ increase in mean vegetation height with a range of 7.5 to $150.0 \mathrm{~cm}$ and $18.5 \%$ less likely to occur for every $10 \%$ increase in canopy closure with a range from 0.0 to $97.8 \%$. Total ground cover, canopy closure, edge density, and percent land cover type (e.g., mature pine, mixed pine/hardwood, shrub/scrub) had minimal influence on nest site selection.

Conclusions: Management of pine savannas for turkey nest sites should focus on creating early-successional vegetation to conceal nests from potential predators. Additionally, we suggest that future studies consider evaluating the influence of spatial scale on turkey nest site selection.
\end{abstract}

Keywords: Georgia, Land cover, Meleagris gallopavo silvestris, Multi-scale, Nest site selection, Pinus palustris, Radio-telemetry

\section{Introduction}

Longleaf pine (Pinus palustris) savannas are considered one of the most biologically diverse systems in North America and support hundreds of species of flora and fauna (Alavalapati et al. 2002). This ecosystem historically occupied over 30 million ha in the southeastern USA (Brockway et al. 2005, Van Lear et al. 2005), but today, approximately 1.2 million ha of longleaf pine savannas remain in isolated patches (Van Lear et al. 2005). This reduction is primarily due to land use change (e.g., conversion to agriculture and establishment of intensively-managed pine plantations where the primary goal is timber production). Additionally, longleaf pine savannas were historically maintained by fire ignited by natural and anthropogenic sources but today are commonly managed by prescribed fire (Komarek

\footnotetext{
* Correspondence: alittle@uga.edu

${ }^{1}$ Warnell School of Forestry and Natural Resources, University of Georgia, 180

E. Green St., Athens, GA 30602, USA

Full list of author information is available at the end of the article
}

1964, Pyne 1982, Robbins and Myers 1992). Frequent fire events ( $\leq 3$ years) are critically important to many species found in this ecosystem. However, changes in government policies have encouraged landowners to exclude fire from their properties (Alavalapati et al. 2002). Without fire disturbance, longleaf pine savannas are replaced by hardwoods and other pine species (Landers et al. 1995, Glitzenstein et al. 2012). Fire is also beneficial to fauna found in a fire-maintained system, as it promotes availability of nesting and brood-rearing cover for groundnesting birds (Dickson 1981, Hurst 1981, Landers 1981) and maintains open, park-like conditions needed by species such as the endangered red-cockaded woodpecker (Picoides borealis; Alavalapati et al. 2002). However, information is needed to fill this knowledge gap in our understanding of wild turkey nest site selection in longleaf pine savannas to direct our future management decisions.

Springer Open

(c) 2016 Little et al. Open Access This article is distributed under the terms of the Creative Commons Attribution 4.0 International License (http://creativecommons.org/licenses/by/4.0/), which permits unrestricted use, distribution, and reproduction in any medium, provided you give appropriate credit to the original author(s) and the source, provide a link to the Creative Commons license, and indicate if changes were made. 
Wild turkey populations are strongly influenced by reproductive success (Palmer et al. 1993, Roberts et al. 1995, Roberts and Porter 1996, Miller et al. 1999, Thogmartin and Shaeffer 2000), and predation is a driver of this success (Speake 1980, Still and Baumann 1990, Miller and Leopold 1992, Lovell et al. 1997). Lower nesting success of turkeys may depend on multi-scale processes including differences in vegetation structure around nest sites, land cover composition and configuration at larger spatial scales, and predator densities (Thogmartin 1999). For example, Martin and Roper (1988) suggested that habitat selection at larger scales surrounding avian nest sites could affect predation risk; therefore, turkeys may select a nest site based not only on the vegetative characteristics at a nest site but also on the surrounding land cover composition. Research is needed to fill this gap in our understanding of wild turkey nest site selection in pine savannas and direct future management decisions. Additionally, few studies have evaluated the role of spatial scale on turkey nest site selection (Thogmartin 1999, Lehman et al. 2008, Fuller et al. 2013).

Wild turkeys primarily select nest sites with greater understory vegetation (Speake et al. 1975, Healy 1981, Badyaev 1995, Byrne and Chamberlain 2013, Streich et al. 2015) and less canopy closure (i.e., shrub/scrub land cover) presumably because these areas are considered important to future broods for foraging and cover (Hillestad and Speake 1970, Hurst and Stringer 1975, Martin and McGinnes 1975, Sisson et al. 1991, Streich et al. 2015). Selection of nest sites with greater understory vegetation may also reduce transmission of olfactory and visual cues to potential nest predators and impede predator foraging efficiency (Bowman and Harris 1980, Lehman et al. 2008). For example, Lehman et al. (2008) found that coyotes (Canis latrans) were the primary predator of turkey nests, and as nesting season progressed, nest survival increased, which they suggested may be a function of reduced precipitation making detection of nesting turkeys increasingly difficult via olfactory senses. Wild turkeys have also been shown to select nest sites in large patches with reduced edge density presumably to reduce the risk of nest predation (Thogmartin 1999). Roads have been shown to be a detrimental influence on wild turkey nest survival (Thogmartin 1999), likely due to the high probability of use of roads as travel corridors by mesocarnivores (e.g., raccoon, Frey and Conover 2006).

Nest site selection is thought to be a hierarchical process (Lazarus and Porter 1985, Martin and Roper 1988, Badyaev 1995, Thogmartin 1999) such that turkeys may first locate a general area to establish a nest and within this area select a suitable nest site. For example, Thogmartin (1999) suggested that wild turkey nest site selection and success likely depends on patterns and processes at multiple spatial scales such as fine-scale vegetation structure within patches (nest site), broader scale land cover composition and configuration, and mesocarnivore densities. Lehman et al. (2008) evaluated the effects of multiple spatial scales on turkey nest site selection and survival and found that successful turkey nests were located in larger land cover patches that contained greater visual obstruction surrounding the nest site. Conversely, Fuller et al. (2013) evaluated the effects of nest site and patch-level metrics on turkey nest site selection and survival and found little support for a hierarchical process concluding that vegetation around the nest site was most important. Recently, Conley et al. (2015) studied mean area used by turkeys during incubation and suggested future habitat assessments associated with turkey nests should be focused on small spatial scales ( $\leq 3 \mathrm{ha}$ ). Uncertainty regarding the influence of spatial scale on turkey nest site selection warrants research to help guide future decisions directed at managing habitats for wild turkeys.

Few research studies have evaluated effects of spatial scale on turkey nest site selection, especially in frequently burned ( $\leq 3$ year fire-return interval) pine savannas. Streich et al. (2015) did not consider the hierarchical process that may influence nest site selection; rather, they evaluated effects of nest site and land cover on nest site selection separately. Additionally, Streich et al. (2015) used distance metrics to evaluate nest site selection, which do not incorporate the juxtaposition and potential importance of multiple land cover types that may be biologically relevant to nest site selection. Frequently burned pine systems provide a unique opportunity to evaluate the effects of spatial scale on turkey nest site selection because this system is primarily characterized by open, park-like conditions with a predominantly herbaceous understory, which is not characteristic of habitat conditions in many previous studies (e.g., Lehman et al. 2008, Fuller et al. 2013). Therefore, our objective was to evaluate whether turkeys exhibited a hierarchical nest site selection in two pine-dominated systems managed by frequent fire ( $\leq 3$ years). Based on previous research (Lazarus and Porter 1985, Martin and Roper 1988, Badyaev 1995, Thogmartin 1999), we hypothesized that nest site selection would follow a hierarchical process such that turkeys would may first locate a general area (larger spatial scale) to establish a nest and within this area select a suitable nest site (smaller spatial scale). Although, this selection process would strongly be influenced by available nesting cover at the smaller spatial scale (Fuller et al. 2013).

\section{Methods}

Study area

Our study was conducted on the 11,735-ha Joseph W. Jones Ecological Research Center at Ichauway (hereafter, 
Jones Center) located in Baker County, Georgia, and the 3900-ha Silver Lake Wildlife Management Area (hereafter, Silver Lake WMA) owned by the Georgia Department of Natural Resources located in Decatur County, Georgia. The Jones Center was comprised of approximately $39 \%$ mature pine ( $>20$ years old), $24 \%$ mixed pine/hardwood, $11 \%$ agriculture/food plot, $8 \%$ young pine ( $\leq 20$ years old), $7 \%$ hardwoods, $4 \%$ scrub-shrub, $3 \%$ wetland, $3 \%$ open water, and $1 \%$ residential/barren. Wiregrass and old-field grasses (e.g., Andropogon spp.) were the dominant understory habitat in the pine and mixed pine/hardwood stands (Goebel et al. 1997). However, >1000 vascular plant species occur on the site (Drew et al. 1998). Silver Lake WMA was comprised of approximately $56 \%$ mature pine (>20 years old), $22 \%$ young pine ( $\leq 20$ years old), $10 \%$ open water, $9 \%$ mixed pine/hardwood, $1 \%$ shrub/scrub, $1 \%$ hardwood, $1 \%$ residential/barren, and $<1 \%$ wetlands and agriculture/ food plots. The Georgia Department of Natural Resources provided all land cover classification data for Silver Lake WMA, which we used to create similar land cover classes across both study sites. Paved, gravel, and dirt road densities were 5.48 and $6.59 \mathrm{~km} / \mathrm{km}^{2}$ on the Jones Center and Silver Lake WMA, respectively. Total rainfall during the nest and brood-rearing season (1 April-31 July) at the Jones Center was $28.32 \mathrm{~cm}$ in 2011, $36.35 \mathrm{~cm}$ in 2012, and $52.02 \mathrm{~cm}$ in 2013. Similarly, total rainfall at Silver Lake WMA was $25.48 \mathrm{~cm}$ in 2011 and $36.55 \mathrm{~cm}$ in 2012 . Average daily temperature at the Jones Center was $25.09{ }^{\circ} \mathrm{C}$ in $2011,24.56{ }^{\circ} \mathrm{C}$ in 2012 , and $23.62{ }^{\circ} \mathrm{C}$ in 2013 (Newton; Georgia Automated Environmental Monitoring Network; http://georgiaweather.net). Likewise, average daily temperature at Silver Lake WMA was $25.77{ }^{\circ} \mathrm{C}$ in 2011 and $25.24{ }^{\circ} \mathrm{C}$ in 2012 (Lake Seminole; Georgia Automated Environmental Monitoring Network; http://georgiaweather.net). Data collection ended in 2012 on Silver Lake WMA but continued for an additional year on the Jones Center.

\section{Turkey capture and monitoring}

We captured female wild turkeys using rocket nets baited with corn during December-March of 2011-2013 and June-August of 2011-2012. We fitted all captured females with serially numbered, butt-end (left leg) and riveted (right leg) aluminum leg bands (National Band and Tag Co., Newport, KY). We also affixed a backpackstyle VHF radio-transmitter, weighing approximately $60 \mathrm{~g}$ (Sirtrack, Havelock North, New Zealand; and Telenax, Playa del Carmen, México) to all females. All birds were released at the capture site immediately after processing. The Institutional Animal Care and Use Committee at the University of Georgia approved all turkey capture, handling, and marking procedures (Protocol \#A2013 05-034-Y1-A0).
We used a handheld, three-element Yagi antenna and Wildlife Materials TRX 2000S receiver (Wildlife Materials, Murphysboro, IL) to locate radio-marked females $\geq 2$ times per week from mid-July to mid-March and $\geq 1$ time per day from mid-March to mid-July. We triangulated each female and recorded the locations using a mobile phone containing Location Of A Signal-SD software (LOAS ${ }^{\mathrm{ma}}$ [2010] Ecological Software Solutions LLC. Hegymagas, Hungary, Version 4.0.3.8.) and a Bluetooth Global Positioning System unit. We considered a female to be incubating if she did not move for three consecutive days during the nesting season. Once a female was determined to be incubating, we approached to within $25 \mathrm{~m}$ of the nest and recorded compass bearings toward the nest to facilitate in detection of the nest following loss or hatch. After termination of incubation, we approached nest sites to determine nest fate, clutch size, and possible brood size, and a GPS location was recorded for future analyses.

\section{Land cover classification}

Pine stands consisted of loblolly, longleaf, slash, and shortleaf (Pinus echinata) pine with $>90 \%$ pine. We separated pine stands into two classes: mature pine and young pine. Mature pine consisted of trees $>20$ years old and in large pole $(12.6-25.4 \mathrm{~cm})$ or saw timber $(>25.4 \mathrm{~cm})$ size classes. Average basal area for mature pine stands was $4.9 \mathrm{~m}^{2}$ (range 0.2 to $12.6 \mathrm{~m}^{2}$ ). Young pine consisted of trees $\leq 20$ years old and in seedling/sapling $(0-12.7 \mathrm{~cm})$ or small pole timber $(12.7-25.4 \mathrm{~cm})$ size classes. Average basal area for young pine was $2.0 \mathrm{~m}^{2}$ (range 0 to $10.43 \mathrm{~m}^{2}$ ).

Mixed pine/hardwood stands contained a variety of species (e.g., loblolly, longleaf, slash pine, southern red oak [Quercus falcata], turkey oak [Quercus laevis], live oak [Quercus virginiana], laurel oak [Quercus laurifolia], and sweetgum [Liquidambar styraciflua]). Mixed pine/ hardwood consisted of stands with 50 to $80 \%$ hardwood or pine. Tree sizes ranged from seedling/sapling through saw timber within these stands; however, most (>90\%) were in the pole to saw timber classes. Average basal area was $2.8 \mathrm{~m}^{2}$ (range 0 to $8.8 \mathrm{~m}^{2}$ ) for pine and $3.2 \mathrm{~m}^{2}$ (range 0 to $20.8 \mathrm{~m}^{2}$ ) for hardwoods.

Hardwood stands consisted of a variety of species (e.g., southern red, turkey, live, laurel oaks, and sweetgum) with tree sizes ranging from seedling/sapling to saw timber; however, most (>90\%) were in the pole to saw timber classes. Average basal area was $9.8 \mathrm{~m}^{2}$ (range 2.9 to $30.1 \mathrm{~m}^{2}$ ) and consisted of $>90 \%$ hardwoods. Agriculture/food plot consisted of cropland, pasture land, wildlife food plots, or horticultural crops (e.g., pecan orchard). Shrub/scrub stands consisted of abandoned agricultural fields and pastures, clear-cuts, grassland, and shrubby areas.

To restore and maintain pine savannas on our study sites, land managers used prescribed fire and mechanical 
hardwood removal. Fire was applied to mature pine, young pine, mixed pine/hardwood, and shrub/scrub land cover types. Prescribed fire was conducted throughout the year with $>95 \%$ of burns conducted during JanuaryJuly. Prescribed fire application occurred in a mosaic fashion, which promoted landscape diversity. Average patch size burned at the Jones Center was 21.41 ha $(\mathrm{SE}=$ 0.83; range 0.02-240.57 ha), whereas average patch size burned at Silver Lake WMA was 14.41 ha $(\mathrm{SE}=0.58$; range $0.66-88.27 \mathrm{ha})$. Fire-return interval typically ranged from 1-3 years, but most $(\geq 95 \%)$ fires applied to our study sites were $\leq 2$ years ( $38.4 \%$, 0 year; $34.9 \%, 1$ year; $21.7 \%, 2$ year; $4.9 \%$ of stands with 3 -year time-since-fire). Land managers often used mechanical removal to remove large off-site hardwoods [e.g., water oak (Quercus nigra)] from within mature pine stands.

\section{Habitat characteristics across scales}

One issue with multi-scale studies is the selection of an appropriate set of scales based on the biology of the species. Biotic and abiotic processes operate and interact at multiple spatial scales on the landscape (Turner 1989), which suggests that no single spatial scale likely exists for multiple landscape metrics that may influence avian nest success and/or survival (Stephens et al. 2005, Webb et al. 2012). Therefore, we evaluated non-random turkey nest site selection at multiple spatial scales (15[nest site], 40-, 80-, 120-, 160-, and 200-m radii) by comparing used (actual nest sites) to available locations (potential nest sites). Specifically, we generated an equal number of random locations (potential nest sites) to used locations (actual nest sites) within each study area boundary to evaluate non-random turkey nest site selection. Although this range of scales was somewhat arbitrarily selected, it was roughly centered on Conley et al.'s (2015) suggestion that future turkey nest ecology studies should focus on nesting habitat $\leq 3$ ha surrounding the nest ( $100-\mathrm{m}$ radius), and the maximum scale was constrained by the availability of high-quality land cover data outside the area of interest. Streich et al. (2015) evaluated turkey nest site selection on the same study sites using 52 nests (including three found opportunistically) from 2011-2012 that contained nest site vegetation metrics. However, they did not consider the potential hierarchical process that may influence turkey nest site selection. We combined the nest site data from Streich et al. (2015) with $22(27.8 \%)$ additional nests sampled in 2013 at the Jones Center to evaluate whether nest site metrics, landscape metrics, or a combination of both influenced nest site selection.

At the nest site (15-m spatial scale), we measured understory vegetation height $(\mathrm{cm})$, percent canopy cover, and percent ground cover immediately following nest hatch or nest loss. Similarly, we measured the same variables at the randomly generated locations (potential nest sites) across the study areas. To evaluate understory vegetation height, we measured the average visual obstruction $(\mathrm{cm})$ at each nest site using a Robel pole (Robel et al. 1970). The Robel pole was placed in the nest bowl and viewed from a distance of $15 \mathrm{~m}$ in each cardinal direction from the nest site at a height of $1 \mathrm{~m}$. We measured percent canopy cover using a spherical densiometer (Lemmon 1956) and percent ground cover using a $1-\mathrm{m}^{2}$ Daubenmire frame (Daubenmire 1959) at the center of the nest bowl and at a distance of $15 \mathrm{~m}$ in each cardinal direction from the nest site. We partitioned ground cover into six cover types: debris, fern, forb, grass, vine, and woody, before combining the six cover types into one variable (total ground cover).

At larger spatial scales (40-, 80-, 120-, 160-, and 200-m radii), we used FRAGSTATS (McGarigal and Marks 1995) with a moving-window analysis to calculate landscape metrics. We calculated the percentage of mature pine, mixed pine/hardwoods, hardwoods, young pine, agriculture/food plots, and shrub/scrub habitat types. We calculated edge density as the total length $(\mathrm{m})$ of edge between all cover classes divided by the total area $\left(\mathrm{m}^{2}\right)$ multiplied by 10,000 to convert to hectares (McGarigal and Marks 1995). We calculated distance to nearest road by calculating the linear distance from each used (actual nest site) to the nearest road (paved, gravel, and dirt) using ArcGIS $^{\circ} 10.2$ (Environmental Systems Research Institute Inc., Redlands, CA, USA). Similarly, we measured the same variables at the randomly generated locations (potential nest sites) across the study areas.

\section{Model development and statistical analysis}

We implemented a three-step hierarchical variable inclusion approach to reduce the number of variables in the final model. First, we used logistic regression in an information-theoretic framework (Burnham and Anderson 2002) to select the best supported scale for each individual variable. The scale producing the lowest value of Akaike's information criterion (AIC; Akaike 1973) corrected for small sample size (AICc; Burnham and Anderson 2002) was retained for additional modeling. For example, we evaluated percent mature pine at 40-, 80-, 120-, 160-, and 200-m radii and selected the scale with the lowest AICc. In cases where multiple models for a landscape variable had AICc scores $<2.0$ units from each other, we selected the scale that corresponded closely to Conley et al.'s (2015) maximum value ( $\leq 3 \mathrm{ha}$ ) suggested for future turkey nest site selection studies resulting in selection of the 80-m scale. We used a generalized linear model (GLM) implemented in R ( $\mathrm{R}$ Core Team 2013) and a use vs. availability resource selection approach to evaluate non-random nest site selection by comparing used (actual nest sites) to available (potential nest sites) in a 
logistic regression framework where nests were represented as a binary response $(1=$ actual nest site; $0=$ potential nest site). Second, after only one spatial scale was selected for each landscape variable, we evaluated pairwise correlations among the nest site, landscape, and distance to nearest road explanatory variables using Pearson correlation. No variables were found to be highly correlated $(r \geq 0.6)$; therefore, we developed a "full" nest site selection model, which contained variables measured at the nest site and landscape scales (Table 1). Using a GLM, we assessed the influence of all covariates in a full nest site selection model simultaneously on nest site selection. Due to small sample size, we combined nest sites for all 3 years across both study sites. We included study site and year as fixed effects in the full model to account for spatial and temporal variation; however, we were not interested in evaluating differences in selection spatially and temporally.

\section{Results}

We monitored 84 nests during 2011-2013 of which 79 were initiated by 45 radio-marked individuals ( 78 adults and 1 juvenile) and 5 nests were found opportunistically. We excluded 12 of the 84 nests from the analysis because vegetation at the nest site was altered by prescribed fire and/or mowing $(n=7)$ and 5 nests that were

Table 1 Variables and scales considered important to Eastern wild turkey nest site selection

\begin{tabular}{ll}
\hline Variable $^{a}$ & Scale (m) \\
\hline Nest site & 15 \\
Mean visual obstruction & 15 \\
Canopy closure & 15 \\
Total ground cover & \\
Landscape & 80 \\
Mature pine (\%) & 80 \\
Mixed pine/hardwoods (\%) & 80 \\
Hardwoods (\%) & 80 \\
Young pine (\%) & 80 \\
Agriculture (\%) & 40 \\
Shrub/scrub (\%) & 40 \\
Edge density & N/A \\
Distance to nearest road &
\end{tabular}

This research was conducted in two pine savannas (Joseph W. Jones Ecological Research Center and Silver Lake Wildlife Management Area) located in southwestern Georgia, USA, 2011-2013

anformation-theoretic approach was used to evaluate each larger landscape variable at multiple spatial scales (i.e., 40-, 80-, 120-, 160-, and 200-m radii). The spatial scale for each landscape variable was selected using Akaike's information criterion (AIC) adjusted for small sample size (AICC). In cases where multiple models for a landscape variable had AICC scores $<2.0$ units from each other, we selected the scale that corresponded closely to Conley et al.'s (2015) maximum value ( $\leq 3 \mathrm{ha}$ ) suggested for future turkey nest site selection studies resulting in the selection of the $80-\mathrm{m}$ scale found opportunistically had limited information. Our final dataset used for analysis consisted of 72 nests.

Mean visual obstruction was the most important predictor of nest site selection followed by percent canopy closure (Table 2). Scaled odds ratios suggested that nests were $26.8 \%$ more likely to occur for every $10 \mathrm{~cm}$ increase in mean vegetation obstruction. Mean visual obstruction at used nest sites was $113.7 \mathrm{~cm}(\mathrm{SE}=3.1)$ and $82.4 \mathrm{~cm}(\mathrm{SE}=5.3)$ at random sites with a range from 7.5 to $150.0 \mathrm{~cm}$. Scaled odds ratios suggested that nests were $18.5 \%$ less likely to occur for every $10 \%$ increase in canopy closure. Mean percent canopy cover at used nest sites was $56.6 \%(\mathrm{SE}=3.4)$ and $64.1 \%$ $(\mathrm{SE}=3.2)$ at random sites with a range from 0.0 to $97.8 \%$. At the nest site scale, total ground cover had little influence on nest site selection. Similarly, at the larger spatial scale, percent land cover type, edge density, and distance to nearest road had little influence on nest site selection.

\section{Discussion}

Wild turkey nest site selection was strongly influenced by vegetative structure at the nest site (15-m scale) relative to other habitat variables. We found that visual obstruction and canopy closure strongly influenced nest site selection, which is consistent with findings of Streich et al. (2015). However, we found habitat metrics measured at larger spatial scales (e.g., percent habitat type) had minimal influence on turkey nest site selection, which is contrary to Streich et al. (2015). Streich et al. (2015) found that turkeys selected nests farther from mature pine and mixed pine/hardwoods and closer to shrub/scrub land cover types than expected. We suggest that the difference we observed is primarily due to the evaluation of multiple spatial scales in the same modeling procedure, compared to separately evaluating nest site and landscape-level metrics on nest site selection as reported in Streich et al. (2015). Our analytical approach accounted for the potential hierarchical process in nest site selection and evaluated influences of land cover metrics measured at multiple spatial scales on turkey nest site selection. Additionally, we used land cover composition (\%) and edge density metrics, which incorporate the land cover composition and structure around the nest sites compared to using distance-based metrics as reported by Streich et al. (2015). Our findings also illustrate the importance of evaluating the influence of spatial scale on wildlife-habitat relationships because metrics measured at larger spatial scales had little influence on where female turkeys established nest sites. This suggests that turkeys are primarily focused on finding nest sites that provide adequate visual obstruction from predators. Furthermore, our study provides evidence that vegetation at the nest site-level is the primary driver of nest site selection in pine savannas managed by frequent prescribed fire ( $\leq 3$ year fire-return interval). 
Table 2 Parameter estimates of nest and landscape variables important to Eastern wild turkey nest site selection

\begin{tabular}{|c|c|c|c|c|c|c|c|}
\hline Variable & Estimate & SE & Scalar & $P$ & Odds ratio & Lower $95 \%$ odds ratio & Upper $95 \%$ odds ratio \\
\hline \multicolumn{8}{|l|}{ Nest site } \\
\hline Mean visual obstruction & 0.237 & 0.065 & $10^{c}$ & $<0.001$ & 1.268 & 1.117 & 1.439 \\
\hline Canopy closure & -0.204 & 0.092 & $10^{\mathrm{d}}$ & 0.027 & 0.815 & 0.680 & 0.977 \\
\hline Total ground cover ${ }^{a}$ & 0.126 & 0.219 & $10^{\mathrm{d}}$ & 0.565 & 1.134 & 0.739 & 1.741 \\
\hline \multicolumn{8}{|l|}{ Landscape-level } \\
\hline Mature pine $(\%)^{b}$ & -0.014 & 0.017 & N/A & 0.397 & 0.986 & 0.955 & 1.019 \\
\hline Mixed pine/hardwoods (\%) & 0.005 & 0.017 & $\mathrm{~N} / \mathrm{A}$ & 0.766 & 1.005 & 0.972 & 1.039 \\
\hline Hardwoods $(\%)^{\mathrm{b}}$ & -0.035 & 0.025 & N/A & 0.173 & 0.966 & 0.919 & 1.015 \\
\hline Young pine $(\%)^{\mathrm{b}}$ & -0.020 & 0.017 & N/A & 0.237 & 0.980 & 0.948 & 1.013 \\
\hline Agriculture $(\%)^{b}$ & -0.019 & 0.024 & N/A & 0.416 & 0.981 & 0.936 & 1.028 \\
\hline Shrub/scrub $(\%)^{b}$ & 0.005 & 0.018 & N/A & 0.773 & 1.005 & 0.971 & 1.040 \\
\hline Edge density $(\%)^{\mathrm{b}}$ & 0.002 & 0.002 & $\mathrm{~N} / \mathrm{A}$ & 0.470 & 1.002 & 0.997 & 1.006 \\
\hline Distance to nearest road & -0.020 & 0.245 & $50^{e}$ & 0.935 & 0.980 & 0.607 & 1.583 \\
\hline
\end{tabular}

This research was conducted in two pine savannas (Joseph W. Jones Ecological Research Center and Silver Lake Wildlife Management Area) located in southwestern Georgia, USA, 2011-2013

${ }^{a}$ Total ground cover: percentage of debris, fern, forb, grass, vine, and woody cover

${ }^{b}$ Refer to Table 1 for spatial scale selected for each variable

'Biologically relevant scaler in centimeters $(\mathrm{cm})$

${ }^{\mathrm{d}}$ Biologically relevant scaler in percent (\%)

${ }^{\mathrm{e}}$ Biologically relevant scaler in meters $(\mathrm{m})$

Mean visual obstruction was the most important predictor of nest site selection followed by percent canopy closure. Our findings are consistent with previous studies that found turkeys select nest sites in areas with increased vegetation height (Badyaev 1995, Chamberlain and Leopold 1998, Byrne and Chamberlain 2013, Fuller et al. 2013). Visual obstruction surrounding nests may reduce transmission of olfactory and visual cues for potential nest predators and impede foraging efficiency by restricting predator movements (Bowman and Harris 1980, Lehman et al. 2008). Fuller et al. (2013) found daily survival rate of turkey nests during incubation increased as percent understory cover (vegetation $<1 \mathrm{~m}$ tall) increased but they also found that nest survival declined with increasing density of woody shrubs and saplings and herbaceous stems $<1 \mathrm{~m}$ tall (understory vegetation density) around the nest. They suggested survival was likely dependent on a balance of sufficient understory cover around nests to provide concealment but not so great as to impede a female's ability to detect and escape predators. Percent canopy closure was also an important predictor of nest site selection. Reduced canopy closure also allows for greater sunlight and presumably greater understory growth.

Contrary to Thogmartin (1999), we found habitat metrics measured at larger spatial scales had little influence on nest site selection. We suggest our lack of support for landscape metrics on nest site selection may have occurred for a couple reasons. First, many multi-scale studies select observational scales without regard to how habitat metrics of interest quantify along the scale continuum (Wheatley 2010). In our case, we arbitrarily selected the larger spatial scales (40-, 80-, 120-, 160-, and $200-\mathrm{m}$ radii) by increasing the buffer size by $40 \mathrm{~m}$ without considering potential among-scale differences in mean or variation of the selected habitat metrics. Therefore, to improve our understanding of why we may have observed little support for the influence of landscapelevel metrics on nest site selection, we conducted a post hoc analysis to evaluate the scale-domain continuum for our selected metrics as suggested by Wheatley (2010). We used the same observational extents for all landscape metrics but also included a radius of $500 \mathrm{~m}$ to determine if larger extents are needed to detect differences in landscape-level metrics on nest site selection in our study. We spaced circular sampling plots systematically throughout the study areas. Sample-plot size corresponded to the chosen observational-extent sizes. Using FRAGSTATS, we calculated percent land cover type and edge density across all observational extents. We then calculated the mean and associated standard deviation for each spatial extent (Fig. 1). Our results illustrated that our metrics were primarily measured on the same domain of scale indicated by minimal differences in the mean and variation of each metric across scales (Fig. 1), which provides support for why our landscape-level metrics may not have influenced turkey nest selection. The lack of variability among the different metrics suggests that our study areas are fairly homogenous as you increase in spatial extent, suggesting that landscape-level 


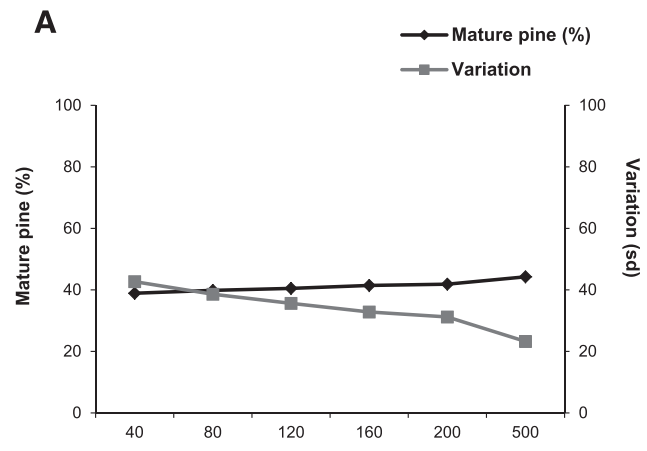

Observational extent ( $m$; radius)
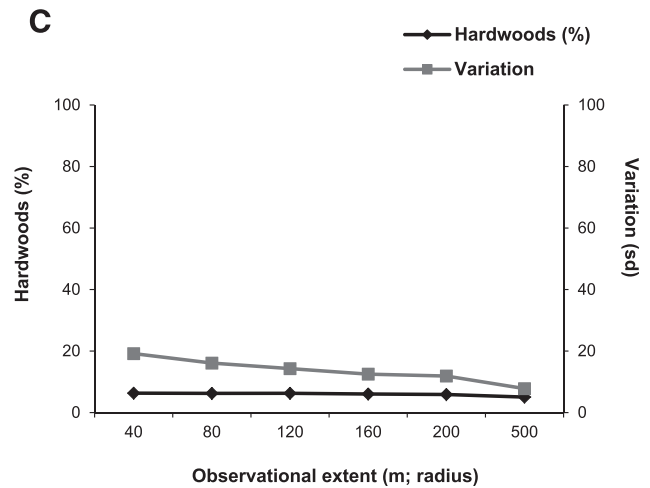

E

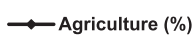

$\rightarrow$ Variation

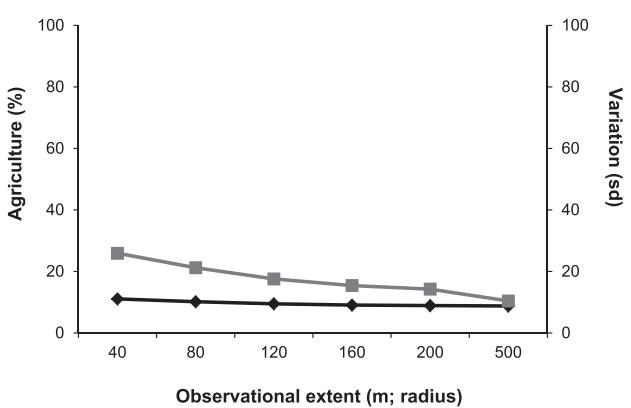

G

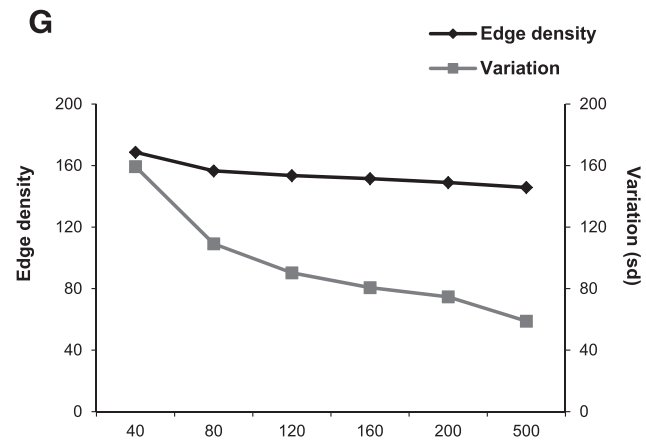

Observational extent ( $m$; radius)

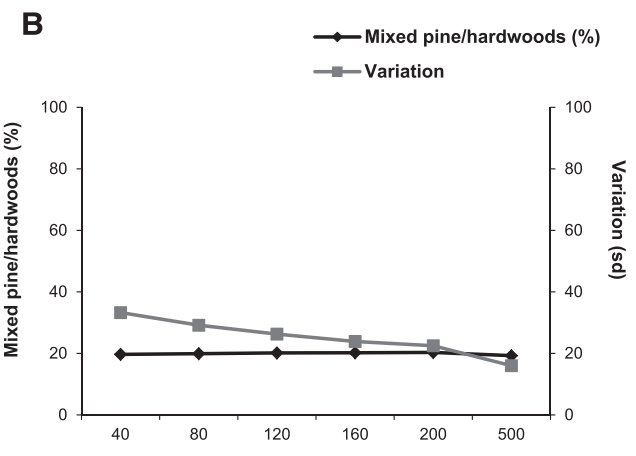

Observational extent ( $m$; radius)
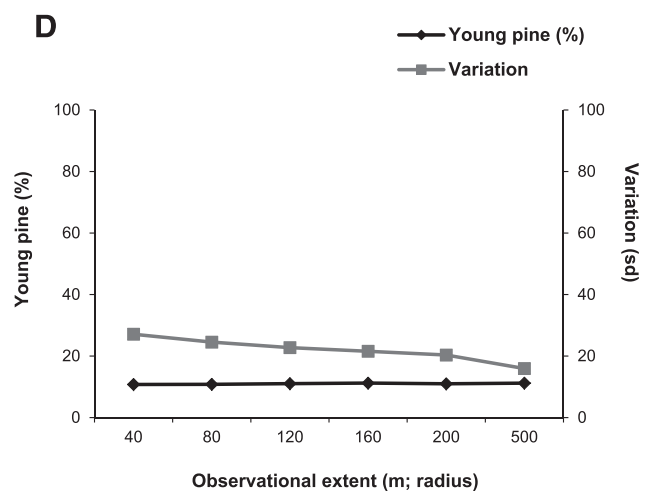

F

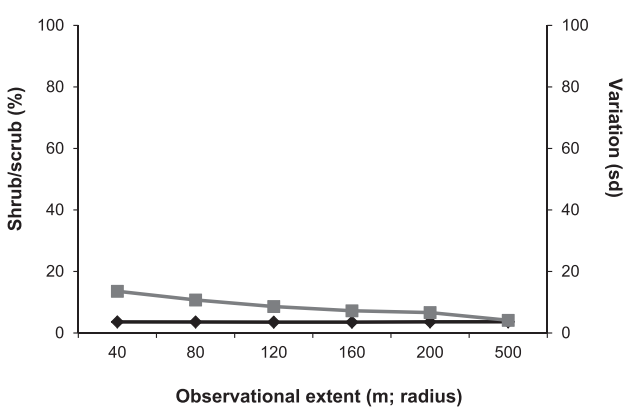

Fig. 1 (See legend on next page.) 
(See figure on previous page.)

Fig. 1 Average values and associated variation for seven landscape metrics across six spatial extents. Grain was held constant [10 m] across all six spatial extents. The research was conducted in two pine savannas (Joseph W. Jones Ecological Research Center and Silver Lake Wildlife Management Area) located in southwestern Georgia, USA, 2011-2013. a Percent mature pine. b Percent mixed/pine hardwood. c Percent hardwood. d Percent young pine. e Percent agriculture. $\mathbf{f}$ Percent shrub/scrub. $\mathbf{g}$ Edge density

metrics may not be an important driver of nest site selection in pine savannas.

Another key difference between our study and Thogmartin (1999) is that we conducted our research in a pine savanna system managed by frequent prescribed fire. Frequent prescribed fire reduces small hardwoods and shrubs resulting in a corresponding increase in grasses and forbs creating open, park-like conditions (Waldrop et al. 1992, Brockway and Lewis 1997, Glitzenstein et al. 2012). Additionally, frequent prescribed fire in pine savannas increases understory plant species richness, diversity, and evenness (Brockway and Lewis 1997), which potentially provides wild turkeys with an abundance of suitable nesting habitat. Previous research has indicated that prescribed fire is an important factor in maintaining quality early-successional understory habitat conditions and herbaceous vegetation while increasing insect abundance for wild turkeys (McGlincy 1985, Landers and Mueller 1986, Exum 1988, Provencher et al. 1998). Our research suggests open, pine savannas managed by frequent prescribed fire ( $\leq 3$ years) and at small scales (12-22 ha) are beneficial for the development of early-successional turkey nesting habitat.

Multi-scale studies facilitate an improved understanding of how scale can influence ecosystem functions (Wheatley and Johnson 2009). Our study is one of only a few studies that has used a multi-scale approach to evaluate the effects of vegetation composition across multiple spatial scales on turkey nest site selection. Fuller et al. (2013) evaluated Eastern wild turkey nest survival in Connecticut as a function of nest site and patch-level habitat metrics and found the nest site scale (vegetation surrounding the nest site) was most important to nest site selection and survival. Lehman et al. (2008) evaluated Merriam's turkey (Meleagris gallopavo merriami) nest site selection and survival in South Dakota as a function of multiple habitat components collected at multiple spatial scales. They provided evidence for a hierarchical nest site selection process because they found land cover patch size (ha) and visual obstruction at the nest site to be the two primary habitat components that influenced nest site selection and survival. More recently, Conley et al. (2015) found that the mean area used by turkeys during incubation was $<3$ ha, suggesting smaller spatial scales may be important to turkey nest site selection. These studies all illustrate the importance of scale when evaluating turkey nest site selection because some habitat components may be important at one spatial scale relative to another.
However, all of these studies illustrate that turkeys are primarily focused on finding nest sites that provide adequate visual obstruction from predators.

\section{Conclusions}

Our research indicates that turkey nest site selection is primarily influenced by vegetative structure immediately surrounding the nest site. Mean visual obstruction and percent canopy closure were the primary drivers of nest site selection on our study sites. Total ground cover, edge density, and percent habitat type (e.g., mature pine, mixed pine/hardwood, shrub/scrub) had minimal influence on turkey nest site selection. Our study suggests that management of pine savannas with frequent ( $\leq 3$ years) prescribed fire-return intervals can be beneficial to turkeys by providing early-successional vegetation for nest site establishment. We suggest land managers balance management objectives of wild turkey habitat management with those of threatened and endangered species (e.g., gopher tortoise [Gopherus polyphemus] and red-cockaded woodpecker [Picoides borealis]) by promoting earlysuccessional vegetation in pine savannas through use of small-scale (12-22 ha) and periodic prescribed fire (23 years).

Multi-scale studies are important for our understanding of how patterns and processes interact and operate on the landscape and influence animal behaviors. Our findings illustrated that turkeys primarily focused on habitat components measured at small spatial scales $(15 \mathrm{~m})$. Therefore, we suggest future turkey nest site selection and survival studies should primarily focus on smaller spatial scales surrounding the nest site as suggested by Conley et al. (2015). Secondly, we suggest that future multi-scale studies may benefit from a preliminary analysis of how mean and associated standard deviation of potential covariates change along the scale continuum as suggested by Wheatley (2010). Understanding how habitat metrics behave across multiple scales may provide additional support for scale choice and interpretation of predictive species-habitat models (Wheatley 2010).

\section{Abbreviations}

AIC: Akaike's information criterion; AICc: Akaike's information criterion corrected for small sample size; GLM: generalized linear model; VHF: very-high frequency. 


\section{Authors' contributions}

ARL designed the study, managed and analyzed the data, wrote the statistical code, and drafted the manuscript. NPN designed the study, provided statistical assistance, and reviewed the manuscript drafts. MJC designed the study and reviewed the manuscript drafts. LMC designed the study, provided statistical assistance, and reviewed the manuscript drafts. RJW designed the study and reviewed the manuscript drafts. All authors read and approved the final manuscript.

\section{Acknowledgements}

We are grateful for the funding provided by the Georgia Wildlife Resources Division through the Wildlife Restoration Program (Grant No. W75), the Joseph W. Jones Ecological Research Center at Ichauway, and the Warnell School of Forestry and Natural Resources at the University of Georgia. We thank the staff at the aforementioned organizations for their technical assistance on this project and M. Streich, C. Perez, D. Colbert, and D. Ruttinger for their assistance with the data collection.

\section{Author details}

'Warnell School of Forestry and Natural Resources, University of Georgia, 180 E. Green St., Athens, GA 30602, USA. ${ }^{2}$ Joseph W. Jones Ecological Research Center at Ichauway, Newton, Georgia 39870, USA.

\section{Received: 13 January 2016 Accepted: 11 April 2016}

\section{Published online: 23 April 2016}

\section{References}

Akaike H (1973) Information theory and an extension of the maximum likelihood principle. In: Petrov BN, Csaki F (eds) Proc of the Second International Symposium on Information Theory. Akademiai Kiado, Budapest

Alavalapati, JRR, Stainback, GA, Carter, DR (2002) Restoration of the longleaf pine ecosystem on private lands in the US South: an ecological economic analysis. Ecol. Economics 40:411-419.

Badyaev AV (1995) Nesting habitat and nesting success of eastern wild turkeys in the Arkansas Ozark Highlands. The Condor 97:221-232

Bowman GB, Harris LD (1980) Effect of spatial heterogeneity on ground-nest depredation. J Wildl Manage 44:806-813

Brockway DG, Lewis CE (1997) Long-term effects of dormant-season prescribed fire on plant community diversity, structure and productivity in a longleaf pine wiregrass ecosystem. For Ecol Manage 96:167-183

Brockway DG, Outcalt KW, Tomczak DJ, Johnson EE (2005) Restoring longleaf pine forest ecosystems in the southern U.S. In: Stanturf JA, Madsen P (eds) Restoration of Temperate and Boreal Forests. CRC Press, Boca Raton, Florida, USA

Burnham KP, Anderson DR (2002) Model selection and multimodel inference: a practical information-theoretic approach. Springer, New York

Byrne ME, Chamberlain MJ (2013) Nesting ecology of wild turkeys in a bottomland hardwood forest. Am Midl Nat 170:95-110

Chamberlain MJ, Leopold BD (1998) Microhabitat characteristics of wild turkey prenest and nest site selection in central Mississippi. Proc Annu Conf Southeast Assoc Fish Wild Agencies 52:274-282

Conley MD, Oetgen JG, Barrow J, Chamberlain MJ, Skow KL, Collier BA (2015) Habitat selection, incubation, and incubation recess ranges of nesting female Rio Grande wild turkeys in Texas. Proc of the Nat Wild Turkey Symp 11:117-126.

Core Team R (2013) A language and environment for statistical computing. R Foundation for Statistical Computing, Vienna

Daubenmire RF (1959) A canopy coverage method of vegetational analysis. Northwest Sci 33:43-64

Dickson JG (1981) Effects of forest burning on songbirds. In: Wood GW (ed) Prescribed fire and wildlife in southern forests. Belle W. Baruch Forest Science Institute of Clemson University, Georgetown, South Carolina, USA

Drew MB, Kirkman LK, Gholson AK Jr (1998) The vascular flora of Ichauway, Baker County, Georgia: a remnant longleaf pine/wiregrass ecosystem. Castanea 63:1-24

Exum JH (1988) Turkey management in southeastern pine woods. Proc of the Game Bird Seminar. Tall Timbers Research, Inc., Tallahassee

Frey SN, Conover MR (2006) Habitat use by meso-predators in a corridor environment. J Wildl Manage 70:1111-1118
Fuller AK, Spohr SM, Harrison DJ, Servello FA (2013) Nest survival of wild turkeys Meleagris gallopavo silvestris in a mixed-use landscape: influences at nest site and patch scales. Wildl Biology 19:138-146

Glitzenstein JS, Streng DR, Masters RE, Robertson KM, Hermann SM (2012) Fire frequency effects on vegetation in north Florida pinelands: another look at the long-term Stoddard Fire Research Plots at Tall Timbers Research Station. For Ecol Manage 264:197-209

Goebel PC, Palik BJ, Kirkman LK (1997) Landscape ecosystem types of Ichauway. Technical Report 97-1., Joseph W. Jones Ecological Research Center, Newton, Georgia, USA

Healy WM (1981) Habitat requirements and habitat management for the wild turkey in the southeast. Virginia Wild Turkey Foundation, Ellison

Hillestad HO, Speake DW (1970) Activities of wild turkey hens and poults as influenced by habitat. Proc Annu Conf Southeast Assoc Fish Wildl Agencies 24:244-251

Hurst GA, Stringer BD (1975) Food habits of wild turkey poults in Mississippi. Proc of the Nat Wild Turkey Symp 3:76-85

Hurst GA (1981) Effects of prescribed burning on the eastern wild turkey. Wood, GW (ed) Prescribed fire and wildlife in southern forests. Belle W. Baruch Forest Science Institute of Clemson University, Georgetown, SC, USA.

Komarek EV, Sr. (1964) The natural history of lightning. Proceedings of the. Tall Timbers Fire Ecol. Conference 3:139-183

Landers $J \mathrm{~L}$ (1981) The role of fire in bobwhite quail management. WoodG. W. Wood, editor. Prescribed fire and wild life in southern forests. Belle W. Baruch Forest Science Institute of Clemson University, Georgetown, SC, USA

Landers JL, Mueller, BS. (1986). Bobwhite quail management: a habitat approach. Tall Timbers Research Station Misc. Pub. 6, Tallahassee, Florida, USA.

Landers JL, Van Lear DH, Boyer WD (1995) The longleaf pine forest of the southeast: requiem or renaissance? Journal of Forestry 93:39-43.

Lazarus JE, Porter WF (1985) Nest habitat selection by Wild Turkeys in Minnesota. Proc of the Nat Wild Turkey Symp 5:67-82

Lehman CP, Rumble MA, Flake LD, Thompson DJ (2008) Merriam's turkey nest survival and factors affecting nest predation by mammals. J Wildl Manage 72:1765-1774

Lemmon PE (1956) A spherical densiometer for estimating forest overstory density. For Science 2:314-320

Lovell CD, Miller DA, Hurst GA, Leopold BD (1997) Relationships between wild turkeys and raccoons in central Mississippi. Proc Eastern Wildl Damage Conf 7:118-129

Martin DD, McGinnes BS (1975) Insect availability and use by turkeys in forest openings. Proc of the Nat Wild Turkey Symp 3:70-75

Martin TE, Roper JJ (1988) Nest predation and nest-site selection of a western population of the Hermit Thrush. Condor 90:51-57.

McGarigal K, Marks BJ (1995) FRAGSTATS: spatial pattern analysis program for quantifying landscape structure. PNW-GTR-351, USDA Forest Service, Pacific Northwest Research Station, Portland, Oregon, USA

McGlincy JA (1985) Wild turkeys and industrial forestry. Proceedings of the Tall Timbers Game Bird Seminar Tall Timbers Research, Inc., Tallahassee, FL, USA

Miller JE, Leopold BD (1992) Population influences: predators. In: Dickson JG (ed) The wild turkey: biology and management. Stackpole Books, Harrisburg

Miller DA, Leopold BD, Hurst GA, Gerard PD (1999) Habitat characteristics of wild turkey nest sites in central Mississippi. Proc Annu Conf Southeast Assoc Fish Wildl Agencies 53:434-443

Palmer WE, Hurst GA, Stys JE, Smith DR, Burk JD (1993) Survival rates of wild turkey hens in loblolly pine plantations in Mississippi. J Wildl Manage 57:783-789

Provencher L, Gobris NM, Rodgers HL, Gordon DR, McAdoo JP (1998) Scientific coordination and adaptive management and experimental restoration of longleaf pine community structure, function, and composition. Annual Report 3 (Dec 97-30 Mar 98). University of Florida, Gainesville, Florida, USA

Pyne SJ (1982) Fire in America: a cultural history of wildland and rural fire. Princeton University Press, Princeton, New Jersey, USA.

Robel RJ, Briggs JN, Dayton AD, Hulber LC (1970) Relationships between visual obstruction measurements and weight of grassland vegetation. J of Range Manage 23:295-297

Roberts SD, Porter WF (1996) Importance of demographic parameters to annual changes in wild turkey abundance. Proc of the Nat Wild Turkey Symp 7:15-20

Roberts SD, Coffee JM, Porter WF (1995) Survival and reproduction of female wild turkeys in New York. J Wildl Manage 59:437-447

Robbins LE, Myers RL (1992) Seasonal effects of prescribed burning in Florida: a review. Tall Timbers Research, Inc., Misc. Pub. No. 8. Tallahassee, Florida, USA. 
Sisson DC, Speake DW, Landers JL (1991) Wild turkey brood habitat use in fire-type pine forests. Proc Annu Conf Southeast Assoc Fish Wild Agencies 45:49-57

Speake DW (1980) Predation on wild turkeys in Alabama. Proc of the Nat Wild Turkey Symp 4:86-101

Speake DW, Lynch TE, Fleming WJ, Wright GA, Hamrick WJ (1975) Habitat use and seasonal movements of wild turkeys in the Southeast. Proc of the Nat Wild Turkey Symp 3:122-130

Stephens SE, Rotella JJ, Lindberg MS, Taper ML, Ringelman JK (2005) Duck nest survival in the Missouri Coteau of North Dakota: landscape effects at multiple spatial scales. Ecol Appl 15:2137-2149

Still HR Jr, Baumann DP Jr (1990) Wild turkey nesting ecology on the Francis Marion National Forest. Proc of the Nat Wild Turkey Symp 6:13-17

Streich MM, Little AR, Chamberlain MJ, Conner LM, Warren RJ (2015) Habitat characteristics of Eastern wild turkey nest and ground-roost sites in 2 longleaf pine forests. J Southeast Assoc Fish Wildl Agencies 2:164-170

Thogmartin WE (1999) Landscape attributes and nest site selection in wild turkeys. The Auk 116:912-923

Thogmartin WE, Schaeffer BA (2000) Landscape attributes associated with mortality events of wild turkeys in Arkansas. Wildl Society Bull 28:865-874

Turner MG (1989) Landscape ecology: the effect of pattern on process. Annu Rev of Ecol and Syst 20:171-197

Van Lear DH, Carroll WD, Kapeluck PR, Johnson R (2005) History and restoration of the longleaf pine-grassland ecosystem: implication for species at risk. Forest Ecol and Management 211:150-165.

Waldrop TA, White DL, Jones SM (1992) Fire regimes of pine-grassland communities in the southeastern United States. Forest Ecol. and Management 47:195-210

Webb SL, Olson CV, Dzialak MR, Harju SM, Winstead JB, Lockman D (2012) Landscape features and weather influence nest survival of a ground-nesting bird of conservation concern, the greater sage-grouse, in human-altered environments. Ecol Processes 1:1-15

Wheatley M (2010) Domains of scale in forest-landscape metrics: implications for species-habitat modeling. Acta Oecologica 36:259-267

Wheatley M, Johnson C (2009) Factors limiting our understanding of ecological scale. Ecol Complexity 6:150-159

\section{Submit your manuscript to a SpringerOpen ${ }^{\circ}$ journal and benefit from:}

- Convenient online submission

- Rigorous peer review

- Immediate publication on acceptance

- Open access: articles freely available online

- High visibility within the field

- Retaining the copyright to your article

Submit your next manuscript at $\gg$ springeropen.com 